
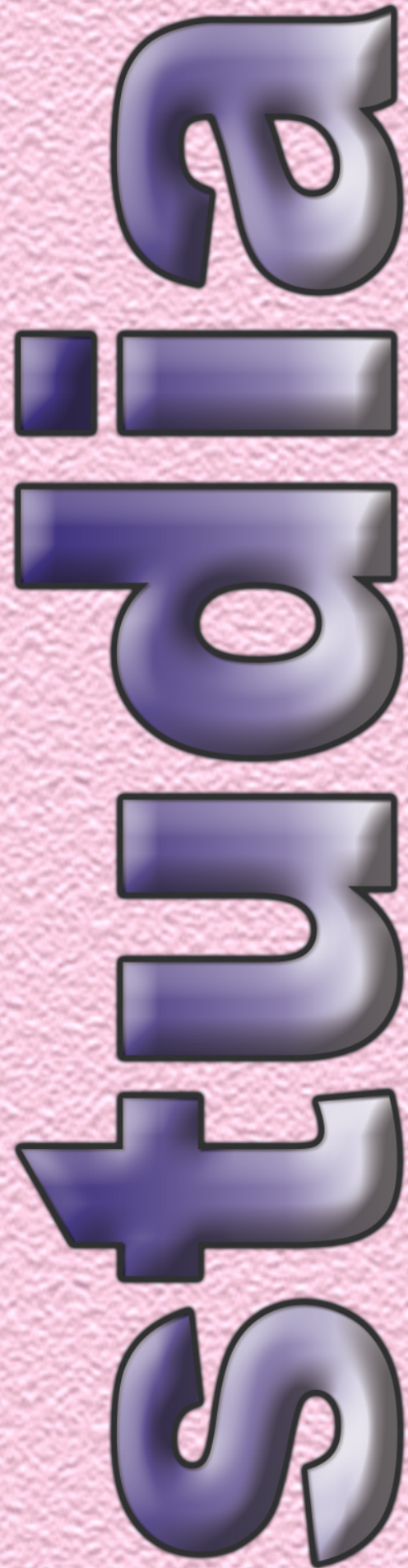

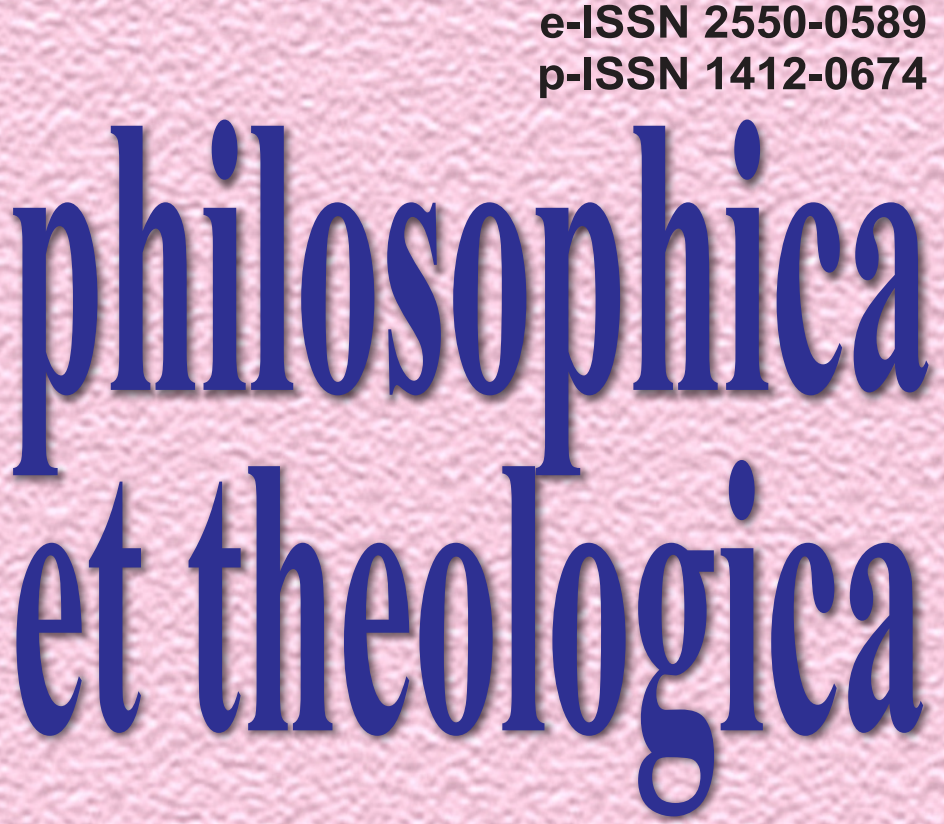

Pandemi Covid 19 dalam Perspektif Visi Kebangkitan Paus Fransiskus

Martinus Dam Febrianto

Formasi Berkelanjutan:

Membermaknakan Kekinian Imamat Edison R.L. Tinambunan

Imajinasi untuk Merawat Kemanusiaan: Pemikiran Martha Nussbaum dalam Pendidikan Humaniora Cicilia Damayanti

Diskursus Hukum Kodrat dan Problem Pascamodernitas Hizkia Fredo Valerian

Polemik Antara Original Event dan Original Purpose dalam Liturgi: Spiritualita Liturgi Ekaristi dalam Perspektif Sejarah Liturgi dan Kitab Suci Robert Pius Manik

Piet Go, Ensiklik Rerum Novarum dan Quadragesimo Anno dan Transformasi Moral Millenial Godlif Sianipar

Applying Bardach and patashnik's Poliy Concept to Educational Leadership Development Effort in the Developing World Gregorius Kukuh Nugroho *****

TELAAH BUKU 


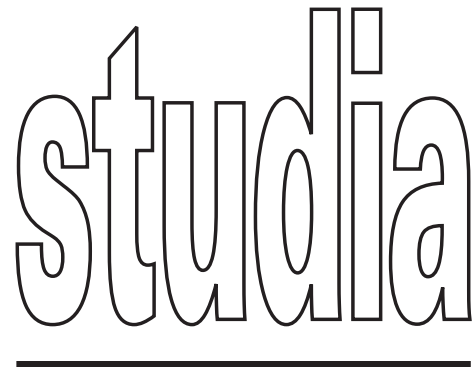

STUDIA PHILOSOPHICA ET THEOLOGICA (ISSN Print 1412-0674 and ISSN Online 2550-0589) is a bilingual (Indonesian and English language) and peer reviewed journal published by Center of Research of Widya Sasana School of Philosophy Theology, Malang. STUDIA specializes in researched papers related to contextualization and inculturation of theology and philosophy from inter-disciplinary-methodological point of view. Journal has 2 issues per year (April and October)

STUDIA welcomes philosophical and theological contributions from scholars with various background of disciplines. This journal uses English and Indonesian Language. STUDIA is an open access journal whose papers published is freely downloaded.

\section{FOCUS AND SCOPE:}

STUDIA focuses on philosophical and theological studies based on both literary and field researches. The emphasis of study is on systematic attempt of exploring seeds of Indonesian philosophy as well as contextualization and inculturationof theology in socio-political-historical atmosphere of Indonesia.

Scope of STUDIA covers various perspectives of philosophical and theological studies from interdisciplinary methodology and cultural-religious point of view of traditions.

\section{PUBLISHER :}

P3M Sekolah Tinggi Filsafat Teologi

Widya Sasana Malang

Jl. Terusan Rajabasa 2,

Malang 65146 Indonesia

Telp. 0341 - 552120

Fax. 0341 - 566676

Email : stftws@gmail.com

Website : ejournal.stftws.ac.id

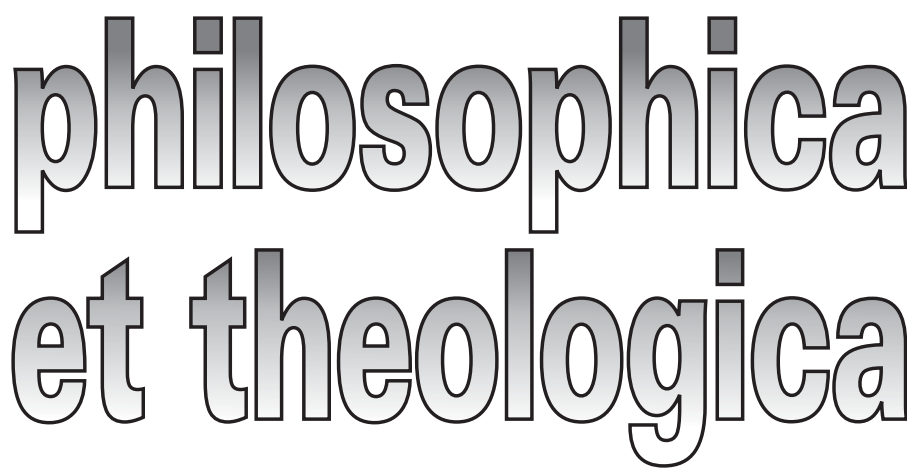

e-ISSN 2550-0589 p-ISSN 1412-0674

Editor in Chief

FX. Eko Armada Riyanto (Google Scholar; h-index: 5); Widya Sasana College of Philosophy Theology, Malang.

\section{Managing Editors}

Edison RL. Tinambunan (Google Scholar; h-index: 1); Widya Sasana College of Philosophy Theology, Malang.

Kurniawan Dwi Madyo Utomo (Google Scholar); Widya Sasana College of Philosophy Theology, Malang.

\section{Editorial Board}

Pius Pandor (Google Scholar; h-index: 2); Widya Sasana College of Philosophy Theology, Malang.

Valentinus Saeng (Google Scholar; h-index: 2); Widya Sasana College of Philosophy Theology, Malang.

Yohanes I Wayan Marianta (Google Scholar); Widya Sasana College of Philosophy Theology, Malang.

Raymundus Made Sudhiarsa (Google Scholar; h-index: 2); Widya Sasana College of Philosophy Theology, Malang.

Alphonsus Catur Raharso (Google Scholar; h-index: 2); Widya Sasana College of Philosophy Theology, Malang.

Petrus Maria Handoko (Google Scholar; h-index: 2); Widya Sasana College of Philosophy Theology, Malang.

Antonius Denny Firmanto (Google Scholar; h-index: 2); Widya Sasana College of Philosophy Theology, Malang.

Carl Sterkens (Scopus ID: ... ; Google Scholar; h-index: 7); Katholic Radboud University, Nijmegen, Niederlands.

Daniel Franklin Pilario(Google Scholar; h-index: 4); Adamson University, Manila, Philippines.

Roland Tuazon (Google Scholar; h-index: 2); Adamson University, Manila, Philippines.

Emanuel P.D. Martasudjita (Scopus ID: 6026801; Google Scholar; h-index: 4); Sanata Dharma University, Yogyakarta.

Johanis Ohoitimur (Google Scholar; h-index: 3); Pineleng College, Manado.

Antonius Eddy Kristiyanto (Google Scholar; h-index: 5); Driyarkara College, Jakarta.

Mudjia Rahardja (Scopus ID: ... Google Scholar; h-index: 10); Maulana Malik Ibrahim Islamic State University, Malang. Justinus Sudarminta (Google Scholar; h-index: 7); Driyarkara College, Jakarta.

English Language Advisor

Maria Lichmann (North Carolina)

Odilia Rahayu Widji Astuti

Indonesian Language Advisor

Didik Bagiyowinadi

Information and Technology

Imilda Retno Arum Sari

Publication Frequency

Studia Philosophicaet Theologica is published two times a year (April and October) 


\section{Studia Philosophica et Theologica}

\section{Author Guidelines}

1. Article must have150-word abstract in both English and Indonesian language and four or five keywords.

2. Article should be between 5000 and 8000 words, inclusive of references and footnotes.

3. Article must be a study based on either literary (text) or field research.

4. Article will be submitted in Word (single-spaced and 12-point font) for consideration by email attachment, beside online submission as required. Authors must $\log$ in before submit their article.

5. Headings:

- First-level headings (e.g. Introduction, Conclusion) should be in bold, with an initial capital letter for any proper nouns.

- Second-level headings should be in bold italics, with an initial capital letter for any proper nouns.

- Third-level headings should be in italics, with an initial capital letter for any propernouns.

6. Notes and Bibliographies please click https://www.dropbox.com/s/y2nb9l3cvb9 fg47/Notes\%20and\%20Bibliography\%20Turabian\%20Style.pdf? $d l=0$.

7. Article submitted will be peer-reviewed by qualified academics; this process may take weeks or months. All submitted papers are subject to review of the editors, editorial board, and reviewers.

8. Author should be willing to respond to questions from readers of their articles; and in case there is correction, author must refine the article as soon as possible.

\section{Guidelines for Book Reviews}

1. Please include, at the beginning: Author, Title, Place, Publisher, Date, number of pages, ISBN of the book reviewed.

E.g., Taylor, Charles. A Secular Age. Cambridge: The Belknap Press of Harvard University Press, 2007. 874+x pp. ISBN-13: 978-0-674-02676-6.

2. The review begin with abstract, three or four keywords and continue with a brief overall description of the book.

3. The review may include:

- The content and its complexity of the book.

- Comments on the author's style and contribution of the book.

- Philosophical or theological methodology of presentation.

- Position of the philosophical or theological arguments in its field.

4. The preferred format for submissions is MS-Word.

5. Review should be about 1500 words long. The name, affiliation and email address of the reviewer should appear at the end of the review. 


\section{Studia Philosophica et Theologica E-ISSN 2550 - 0589 \\ ISSN 1412-0674 \\ Vol. 21 No. 1 April 2021 \\ Hal. 1 - 131}

\section{DAFTAR ISI}

\section{ARTIKEL}

Pandemi Covid 19 dalam Perspektif Visi Kebangkitan

Paus Fransiskus

Martinus Dam Febrianto

$1-23$

Formasi Berkelanjutan: Membermaknakan Kekinian Imamat

Edison R.L. Tinambunan

Imajinasi untuk Merawat Kemanusiaan:

Pemikiran Martha Nussbaum dalam Pendidikan Humaniora

Cicilia Damayanti.....

Diskursus Hukum Kodrat dan Problem Pascamodernitas

Hizkia Fredo Valerian

$67-81$

Polemik Antara Original Event dan Original Purpose

dalam Liturgi: Spiritualitas Liturgi Ekaristi dalam Perspektif

Sejarah Liturgi dan Kitab Suci

Robert Pius Manik

$82-96$

Piet Go, Ensiklik Rerum Novarum dan Quadragesimo Anno dan Transformasi Moral Millenial

Godlif Sianipar.....

Applying Bardach and Patashnik's Policy Concept to Educational Leadership Development Effort in the Developing World

Gregorius Kukuh Nugroho 


\section{TELAAH BUKU}

Teologi Terlibat: Politik dan Budaya dalam Terang Teologi

Antonius Ignasius Nggino Tukan ................................................... 128 - 131 


\title{
PIET GO, ENSIKLIK RERUM NOVARUM \\ DAN QUADRAGESIMO ANNO DAN \\ TRANFORMASI MORAL MILLENIAL
}

\author{
Godlif Sianipar \\ Universitas Katolik Santo Thomas Sumatera Utara \\ Email: godlif@yahoo.com
}

\begin{abstract}
This research discusses about moral problems that are occurring daily in the society and the Church as pointed out by Piet Go Twan An. Those moral problems are the problems created by firstly the Indonesian Marriage Law; secondly the problem of pastoral care among the priests should be reformed to suit inter-personal relations with God's people so that the Church's missions are receivedeffectively and efficiently; thirdly the problem of corruption in the government and the needs for the Church to be pro-active in eradicating corruptions; and the last point is the problem of homosexuality or LGBT issues. Solution is offered by moral transforming among its people (the faithful and the people) namely personal ethic transformation based on the Papal Encyclic Rerum Novarum and Quadragesimo Anno. This research is to address the question of how much personal moral transformation is needed to overcome moral problems in the society. The data and samples of this research are 895 people of Christians and Catholics in Medan in 2010.The data were formerly used for other research purposes. By using the Analysis Factor and SEM methods, it is predicted that there will be an increase of 0.08 on the transformation of personal morals if there is an effort of 0.28 points to improve the morals of the faithful and the people of Medan.
\end{abstract}

Keywords: church social teachings, moral degradation, moral transformation, Piet Go TwanAn.

\section{Abstrak}

Penelitian ini mendiskusikan masalah moral yang sedang terjadi di masyarakat dan Gereja seperti yang diungkapkan oleh Piet Go Twan An. Masalah moral aktual tersebut adalah masalah Undang-Undang Perkawinan Indonesia yang belum mempertimbangkan secara mendalam terkait dengan hak-hak asasi manusia dan pendidikan anak-anak dalam keluarga; masalah reksa pastoral dalam Gereja yang perlu dibenahi dengan kedekatan inter-personal dengan umat agar ajaran dan misi Gereja efektif sampai; masalah perlunya agar Gereja pro-aktif memberantas sistem hukum yang korup dan tidak manusiawi; dan masalah teologi kerahiman Tuhan yang perlu dikedepankan dalam 
menghadapi persoalan LGBT. Solusi untuk menjawab masalah moral tersebut adalah dengan transformasi moral personal berdasarkan usulan Ajaran Sosial Gereja Rerum Novarum dan Quadragesimo Anno. Seberapa besarkah transformasi moral personal yang dibutuhkan untuk mengatasi masalah moral di masyarakat? Penelitian ini mengambil data dan sampel warga Kristen/ Katolik di kota Medan sebanyak 895 orang pada tahun 2010 yang lalu. Data penduduk kota Medan ini pernah dipakai untuk kepentingan penelitian lain. Dengan menggunakan metode Faktor Analisa dan SEM didapatkan hasil prediksi bahwa akan nada kenaikan skor sebesar 0,08 terhadap transformasi moral personal bila diadakan upaya perbaikan moral sebesar 0,28 poin bagi warga di kota Medan.

Kata Kunci: ajaran sosial gereja, degradasi moral, Piet Go TwanAn, transformasi moral.

\section{Pengantar}

Dalam beberapa dasawarsa belakangan ini, dari informasi teknologi pemberitaan, banyak muncul persoalan-persoalan yang terkait dengan masalah moral di masyarakat dan di dalam hidup menggereja. ${ }^{1}$ Ada beberapa persoalan moral yang mengemuka menurut Teolog Moral Indonesia Piet Go Twan An. Pertama adalah tentang kawin campur. Masalahnya adalah bahwa hukum perkawinan di Indonesia tidak mengenal istilah kawin campur. Undang-undang perkawinan Nomor 1 Tahun 1974 menyatakan bahwa sebuah perkawinan baru dikatakan sah bila telah dilakukan menurut hukum masing-masing agama/kepercayaan. Ini berarti bahwa kedua calon pengantin harus seiman dan tidak ada celah untuk kawin campur. Peraturan perkawinan yang sedemikian memungkinkan untuk pindah agama. Satusatunya agama yang mengizinkan kawin campur adalah agama Katolik. Artinya, pasangan pengantin yang akan diberkati di gereja Katolik tidak harus masuk Katolik; cukup bila salah satu pasangannya adalah Katolik serta segala persyaratan untuk dinikahkan telah dipenuhi. Piet Go (2008: 2) mengatakan:

Pertimbangan kita (Katolik) semata-mata demi hak asasi manusia. Persoalan pertama yang dipikirkan gereja adalah pendidikan anak-anak. Orang tua tentu saja ingin mewariskan harta berharga kepada keturunannya, termasuk imannya. La, di sini ada dua iman. Apakah agama Katolik yang diajarkan untuk anak-anak, atau Islam misalnya? Tarik menarik kepentingan sejak awal hidup berumah tangga ini dikhawatirkan (akan) mengganggu kebahagiaan perkawinan mereka. ${ }^{2}$

1 Agus Tridiatno, "Masalah-Masalah Moral Masyarakat di Surat Kabar: Studi Kasus terhadap Halaman 'Kasus' di Surat Kabar Harian Kedaulatan Rakyat", Jurnal Ilmu Komunikasi 2, no. 2 (Desember 2005): 162-3.

2 "Kawin Campur Mengancam Gereja", Iman Katolik, Diakses 18 Juli 2020, https:// imankatolik.wordpress.com/2008/09/17/kawin-campur-mengancam-gereja. 
Persoalan moral yang lain adalah soal penderitaan dan kematian. Tidak banyak orang yang suka menderita, apalagi kalau dia harus mati meninggalkan dunia ini dan orang-orang yang dicintainya. Kedua persoalan ini menakutkan bagi banyak orang. Piet Go berpendapat:

Sehubungan dengan kurangnya pemahaman umat akan makna salib dan penderitaan, banyak orang yang mencoba menghindarinya dengan mengikuti ajaran-ajaran baru dari "gereja-gereja Haleluya" (Gereja-gereja Baptis) yang khotbah, pujian, keplokan, celetukan, interupsinya penuh dengan kata Haleluya" - ini justru tidak memahami salib. Orang lebih senang mencari keberuntungan lewat cara-cara mistis, dengan mengesampingkan Yesus Kristus"..$^{3}$ Lebih lanjut dia mengatakan, "Kurangnya pemahaman ini justru dipertajam oleh pastoral yang kurang mengena. Petugas pastoral, khususnya pastor, tidak memanfaatkan momen Prapaskah dan Paskah untuk menyadarkan umat tentang masalah penderitaan dan kematian itu. Banyak sekali kesempatan yang tersia-siakan. ${ }^{4}$

Karena itulah Piet Go mengemukakan supaya penderitaan dan kematian tidak lagi menjadi hal yang menakutkan:

Kita harus melihat makna penderitaan dan kematian itu. Manusia dewasa ini harus menghayati penderitaan dan kematian. Petugas pastoral harus lebih akrab lagi antara umat melalui kunjungan ke rumah umat, misalnya. Dengan demikian, suka duka bersama dapat kita bagikan. Juga harus ada upaya selektif dari Gereja untuk memberikan kesadaran yang tepat mengenai makna penderitaan dan kematian". ${ }^{5}$

Hal moral yang ketiga adalah tentang hukum mati. Indonesia masih menganut hukum kolonial yang mengizinkan diberlakukannya hukuman mati. Piet Go menanggapinya dengan mengatakan:

Since we have to respect human dignity, the Church teaches that only God has the right to determine the lives of human beings. Pope John Paul II's encyclical Evangelium Vitae (The Gospel of Life) and the 1992 Catechism of the Catholic Church as explaining the Church's position on the death penalty. This stance is not absolute; the tendency is toward abolition of capital punishment. The pope writes in Evangelium Vitae that capital punishment might be justified when it would not be possible otherwise to defend society, but that such cases are very rare, if not practically non-existent. We will only promote and nurture the culture of loving life. Those who violate civil law must be punished. But that execution can only be a last resort". 6

Bagi Piet Go, alasan mengapa Katolik menolak hukum mati adalah karena Tuhan sendirilah yang menentukan mati hidupnya manusia. Karena itu, hidup manusia harus dihormati. Hukuman mati boleh diberlakukan hanya

3 "Banyak Umat Tidak Paham Salib", Iman Katolik, Diakses 18 Juli 2020 https://imankatolik. wordpress.com/2008/08/28/banyak-umat-tidak-paham-salib/.

4 Ibid.

5 Ibid.

6 "Theologian, Rights Activists Decry Death Penalty as Flawed, Wrong", UCA News, Diakses 18 Juli 2020, https://www.ucanews.com/story-archive/?post_name=/2003/03/07/theologian-rightsactivists-decry-death-penalty-as- flawed-wrongEpost_id=22103. 
bila tidak ada cara lain lagi untuk melindungi masyarakat. Hukuman mati dilaksanakan hanya kalau itu merupakan cara akhir untuk menghukum seorang terpidana. Lebih lanjut, Piet Go mengatakan:

In the current context of Indonesia, where organized crime and corrupt people control the justice system, the death penalty has noimpact. On the contrary, even the innocent are punished". ${ }^{7}$

Karena sistem hukum di Indonesia ini dikuasai atau dipimpin oleh orangorang yang rendah moralnya, hukuman mati sebenarnya tidak begitu efektif, terlebih-lebih juga karena banyak orang yang tidak bersalah dihukum.

Hal terakhir adalah tentang Lesbian, Gay, Biseksual, Transgender (LGBT). Kaum LGBT kerap menjadi kelompok minoritas yang mengalami marginalisasi, diskriminasi dan tak dihormati hak-haknya serta keanekaragaman seksualitasnya. Menurut Piet Go:

Dalam antropologi kristiani, pria dan perempuan saling melengkapi serta manusia tak dibenarkan memilih sendiri jenis kelaminnya. Oleh karena itu, LGBT bukanlah orientasi seksual yang semestinya. ${ }^{8}$

Ada beberapa referensi utama dalam Katolik yang terkait dengan homoseksualitas yaitu: Persona Humana; Amanat Paus Yohanes Paulus II kepada para Uskup AS (1979); Surat kepada para Uskup Gereja Katolik tentang reksa pastoral orang homoseksual (1986); Beberapa pertimbangan tentang jawaban untuk usul non diskriminasi orang homoseksual (1992); Katekismus Gereja Katolik 2357-2359; dan pandangan tentang usul memberi pengakuan legal persatuan orang-orang homoseksual (2003). Dalam referensi utama tersebut, menurut Piet Go, muncul beberapa gagasan.

Pertama, dibedakan antara kecenderungan dan aktualisasi dalam perbuatan yang tak dibenarkan karena dianggap bertentangan dengan tata penciptaan (Antropologi Kristiani) dan karenanya secara intrinsik (dari kodratnya, bukan ketentuan manusia) buruk. Kedua, pengaruh Kitab Suci antara lain beberapa kalimat dari Santo Paulus. ${ }^{9}$

Selanjutnya, Piet Go menegaskan:

Sikap Gereja adalah bahwa Gereja tidak membenarkan "perkawinan" homo (yang habitat memuat banyak hubungan seks). Gereja Katolik terkenal keras di bidang moral seksual yang bagi banyak orang amat eksistensial (mengenai hidup pribadi) yang mau tak mau, benar atau tidak, tercermin dalam wajah yang keras juga. Salah satu akibatnya, seperti dapat disimpulkan dari angket menjelang Sinode para Uskup 2014, banyak orang Katolik kurang mengindahkan ajaran Gereja dan jalan sendiri. Kritik tak hanya datang dari Perserikatan Bangsa-bangsa (PBB), melainkan dari umat Katolik sendiri, bahkan dari Paus Fransiskus. Dengan sikap keras itu, Paus

7 Ibid.

8 "Mereka Harus Kita Kasihi", Majalah HIDUP Katolik, Diakses 18 Juli 2020, http://majalah. hidupkatolik.com/2016/11/14/1939/mereka-harus-kita-kasihi/.

9 Ibid. 
Fransiskus melihat wajah Gereja yang kurang mengedepankan sifat Tuhan yang maha rahim dan kurang menampilkan agama Katolik sebagai kabar gembira yang membebaskan. Oleh karena itu Paus Fransiskus mengambil sikap positif dengan pewartaan yang lebih seimbang, teladan hidup sederhana, serta mengutamakan pelayan dan orang miskin. ${ }^{10}$

Konkretnya, beliau melanjutkan:

Dalam menyikapi homoseksualitas dan LGBT, Paus Fransiskus membuat sikap pastoral yang mengedepankan Kerahiman Tuhan. Bahkan dalam beberapa pidatonya, Paus Fransiskus juga mengungkapkan sesuatu yang mengejutkan dan sensasional: "Bila seseorang homoseksual dan mereka mencari Tuhan, siapakah saya untuk mengadilinya? Orang-orang ini tak boleh mengalami diskriminasi dan dikucilkan. Mereka adalah saudara-saudara kita". Sikap dari penilaian keras tak harus ditarik sikap yang keras pula. Berkali-kali Paus Fransiskus mengingatkan perlunya penegasan (discernment) dan memperhatikan keadaan manusia dalam penerapan prinsip yang tak begitu saja dikenakan pada orang yang sering berada dalam keadaan yang amat sulit. Keluarga harus menyikapi anak "homo" dengan terus mencintai sepenuhnya dan membantu menerima diri mereka seperti adanya. Untuk hal integrasi, sejauh perlu mereka juga disiapkan untuk hidup dalam masyarakat dan dibantu menjalani hidup sebagai anggota Gereja. ${ }^{11}$

Secara ringkas, keempat persoalan moral di atas dikemukakan dalam empat poin penting di bawah ini:

1. Masalah Undang-undang Perkawinan Indonesia yang belum mempertimbangkan secara mendalam terkait dengan hak-hak asasi manusia dan pendidikan anak-anak dalam keluarga.

2. Reksa pastoral dalam Gereja perlu dibenahi dengan kedekatan inter-personal dengan umat agar ajaran dan misi Gereja efektif sampai.

3. Perlunya agar Gereja pro-aktif memberantas sistem hukum yang korup dan tidak manusiawi.

4. Teologi Kerahiman Tuhan perlu dikedepankan dalam menghadapi persoalan LGBT.

Esensi keempat hal moral di atas menunjukkan kepada kita bahwa ada persoalan moral yang sedang digeluti oleh masyarakat Indonesia. Piet Go telah mengangkatnya ke permukaan sebagai masalah moral hidup menggereja di Indonesia. Penelitian ini berupaya mendeskripsikan transformasi personal moral umat Kristiani di Medan berdasarkan data tahun 2010 dan memprediksikan besaran perubahan yang akan terjadi bila dilakukan transformasi personal moral pada tingkat-tingkat tertentu. Memang transformasi personal moral umat Kristiani yang akan diteliti di sini tidak persis sama dengan persoalan transformasi moral seperti yang diungkapkan oleh Piet Go, namun akan memberikan gambaran kepada kita transformasi personal moral apa

10 Ibid.

11 Ibid. 
yang akan terjadi di kalangan umat Kristiani di Indonesia pada umumnya dan di Medan pada khususnya.

\section{Pentingnya Transformasi Moral Personal dalam Rerum Novarum}

Tulisan ini akan berangkat dari Ajaran Sosial Gereja Rerum Novarum yang ditulis oleh Paus Leo XIII. Leo XIII mengatakan:

Of these facts there cannot be any shadow of doubt: for instance, that civil society was renovated in every part by Christian institutions. ${ }^{12}$

Masyarakat butuh disembuhkan. Kesembuhan itu hanya dapat terlaksana bila orang-orang kembali menganut hidup dan ajaran Kristiani. Kalau masyarakat yang berantakan mau dipulihkan, titik tolak yang paling tepat ialah kembali kepada asal mulanya. Kesempurnaan semua perserikatan tercapai bila tujuan mereka mencari dan mencapai tujuan mereka didirikan. Itu akan terwujudkan, bila semua kegiatan sosial bersumber pada penyebab yang sama, yang melahirkan masyarakat. Oleh karena itulah meninggalkan prinsip-prinsip asali berarti menderita kehancuran, dan kembali ke prinsipprinsip itu berarti pulihlah keutuhan. Hal yang sama dikutip oleh Paus Pius XI dalam ajaran sosialnya Quadragesimo Anno

Dua hal yang terpenting yakni reformasi institusi dan perbaikan moral (Two things are especially necessary: reform of institutions and correction of morals). ${ }^{13}$

Reformasi institusi dan perbaikan moral menjadi dua hal yang terpenting untuk penyembuhan masyarakat menurut Rerum Novarum dan Quadragesimo Anno. Namun demikian, seperti yang dikatakan oleh Paul Hanly Furfey, seorang imam Diosesan dan sosiolog dari The Catholic University of America:

Institutions are the product of men. If individuals are immoral, their institutions will be immoral also. Goodmen are the basis of good institutions. ${ }^{14}$

Furfey mengindikasikan bahwa bersih tidaknya suatu institusi tergantung pada bersih tidaknya individu yang ada dalam institusi tersebut, Correction of moralsis more basic than there form of institutions. ${ }^{15}$ Sehingga penyembuhan masyarakat erat terkait dengan penyembuhan moral setiap individunya.

Penyembuhan atau reformasi moral masyarakat dengan demikian tidak bisa melupakan aksi moral dari dari masing-masing anggotanya. Dengan demikian kedua hal tersebut bukan merupakan dua program yang berbeda, namun merupakan satu program dengan dua bagian yang berbeda. Furfey mengungkapkan hal tersebut di atas dengan kata-kata:

12 Paus Leo XIII, Rerum Novarum, Art. 27.

13 Paus Pius XI, Quadragesimo Anno, Art. 77.

14 Paul Hanly Furfey,"Personalistic Social Action in the Rerum Novarum and Quadragesimo Anno", The American Catholic Sociological Review, Vol. II No. 4 (1941): 204. 
Organized action and personalistic action are not two alternative programs. They are two parts of one program. ${ }^{16}$

Malah dengan contoh yang ekstrim Furfey mengungkapkan:

The totalitarian countries of Europe have destroyed Catholic organizations; but they cannot destroy Catholic life. ${ }^{17}$

Dengan contoh tersebut, Furfey mau mengungkapkan bahwa aksi moral anggota masyarakat dapat berlangsung walaupun itu tanpa melibatkan organisasi, institusi atau masyarakat itu sendiri. Ini berarti bahwa aksi moral individu itu menjadi penting karena kalau aksi moral tersebut ditiadakan maka terjadilah pengeroposan moral masyarakat dan masyarakat menjadi sakit seperti yang telah disampaikan oleh Piet Go di atas.

\section{Inspirator Rerum Novarum}

Uskup W. E. von Ketteler diangkat oleh Vatikan menjadi Uskup Agung Mainz pada tahun 1850. Namun, dua tahun sebelum ia diangkat menjadi uskup, pada tahun 1848 ketika ia masih menjabat sebagai pastor paroki di Mainz, von Ketteler memulai suatu gerakan sosial di Jerman yang dikenal sebagai Gerakan Sosial Gereja Katolik "Social Catholicism". ${ }^{18}$ Gerakan sosial tersebut dimulainya ketika semua orang Katolik di Jerman (Katholikentag) berkumpul di Frankfurt. Dalam pertemuan itu, semua peserta berharap agar dia berbicara tentang konstitusi negara tersebut namun yang terjadi adalah Ketteler berbicara tentang lebarnya jurang kesenjangan antara yang kaya dan miskin di Jerman, dan semakin bertambahnya kemiskinan di negara tersebut. Ketteler berpendapat bahwa Gereja harus berbuat sesuatu untuk mengatasi masalah tersebut.

Dari ceramahnya di Katholikentag 1848 inilah dimulai Social Catholicism di Jerman. Uskup von Ketteler mendasarkan gerakan sosial tersebut atas ajaran Thomas Aquinas dan menerbitkan tulisannya yang bernuansa sosialisme dan kritis terhadap kapitalisme. Sebagai gerakan sosial ia mengembangkan sikap dan tanggapan bagaimana Gereja seharusnya menanggapi penyakitpenyakit sosial masyarakat pada saat itu. Gerakan sosial di Jerman ini memperbaiki dan mempertajam prinsip-prinsip sosial Gereja Katolik Universal.

Pada tanggal 5 September 1869 dihadapan sidang para Uskup di Jerman ia mengusulkan beberapa hal terkait dengan praktek-praktek yang salah selama ini dalam sistem industri di Jerman, antara lain melarang pekerja anak-

15 Ibid, 205.

16 Ibid. 205.

17 Ibid. 205.

18 Marvin L. Krier Mich, Catholic Social Teaching and Movements (CT: Twenty-Third Publications, 2004), 7-9. 
anak; membatasi jam kerja buruh pabrik; memisahkan tempat kerja pria dari wanita; menutup tempat-tempat kerja yang jorok; istirahat kerja pada hari Minggu; kewajiban memperhatikan kesejahteraan pekerja difabel (seseorang yang memiliki kemampuan berbeda); dan pengawas pabrik yang ditunjuk oleh Negara. ${ }^{19}$ Upaya Uskup Ketteler tersebut membuat dia di Jerman dikenal sebagai "pastor sosialis" 20 dan membuat Jerman dikenal sebagai negara yang terdepan dalam gerakan sosial Gereja Katolik. Ia membangunkan Gereja dan masyarakat untuk melihat masalah-masalah sosial yang timbul di masyarakat. Inilah akar dari ensiklik Rerum Novarum tersebut.

\section{Transformasi Moral Masyarakat}

Pertanyaannya sekarang adalah siapkah setiap warga masyarakat melakukan pembaharuan moral diri masing-masing dan apakah bentukbentuk dari pembaharuan tersebut? Paus Pius mengungkapkan:

What we have taught about there construction and perfection of social order cansurely in no wise be brought to realization without reform of morality, the very record of history clearly shows. ${ }^{21}$

Dengan demikian mau tidak mau setiap orang dalam masyarakat harus mau membaharui moralnya untuk mewujudkan reformasi moral di masyarakat. Paus Leo menekankan bahwa kebaikan-kebaikan dalam masyarakat harus dilakukan dalam bentuk-bentuk keutamaan. ${ }^{22}$ Jadi, pembaharuan moral di masyarakat harus menjadi keutamaan tiap-tiap individu anggota masyarakat.

Aksi moral dan aksi sosial yang harus diwujudkan setiap individu anggota masyarakat, menurut Sri Paus adalah melakukan keutamaan dalam bentuk mewujudkan keadilan dan karitas,

Hence, the instituions themselves of people sand, particularly those of all social life, ought to be penetrated with this justice, and it is most necessary that it be truly effective, that is, establish a juridical and social order which will, as it were, give from and shape to all economic life. Social charity, more over, ought to be as the soulof this order, an order which public authority ought to be ever ready effectively to protect and defend. ${ }^{23}$

Bertindak adil dan berderma adalah aksi moral dan aksi sosial yang diharapkan untuk menyembuhkan masyarakat.

19 A. Eddy Kristiyanto, "Mengenali Konteks Ajaran Sosial Gereja Katolik Abad XIX", Orientasi Baru, Vol. 21, No. 1, (April 2012): 43-44.

20 Ibid, 42.

21 Paus Pius XI, Quadragesimo, Art. 97.

22 Paus Leo XIII, Rerum, Art. 27.

23 Paus Pius XI, Quadragesimo, Art. 88. 


\section{Transformasi Moral Personal di Kota Medan}

Tujuan penelitian ini adalah untuk meneliti transformasi moral personal orang-orang Kristen dan Katolik di kota Medan - Sumatera Utara dengan memilih sampel yang dipilih secara acak (random) menyebar di semua Kecamatan di Kota Medan dengan menggunakan data yang telah dikumpulkan pada tahun 2010 yang lampau. Partisipan penelitian ini yang bersedia ada berjumlah 895 orang (51 persen wanita dan 48 persen Pria). Mereka adalah warga Medan yang berusia di antara 20 tahun hingga 78 tahun dengan pekerjaan bervariasi seperti Guru (28 persen), Pegawai swasta (15 persen), Usaha sendiri (17,5 persen), Ibu rumah tangga (7,5 persen), PNS (9,9 persen), Pedagang ( 3 persen), Sopir ( 2 persen), Ahli tertentu (1,2 persen) dan Pensiunan (1,1 persen). Ada pula responden penelitian ini yang berprofesi Polisi/TNI, Dosen, Pegawai BUMN, Kepala Desa, Pastor, Supervisor yang masing-masing jumlahnya di bawah 1 persen.

Selain itu, tingkat pendidikan responden pun bervariasi. Kebanyakan tingkat pendidikan responden adalah tamat SMA (26,6 persen), D-3 $(6,7$ persen), Tamat SMP (4 persen), Tamat SMK (3,1 persen), S-2 (2,5 persen), dan selebihnya adalah tamat SD, tamat SPG, D-1 (1 persen ke bawah). Dengan tingkat pendidikan bervariasi seperti yang tampak di atas, ada sekitar 39 persen responden yang mengakui sendiri tipe radikal beragamanya Moderat, 25,1 persen Fundamentalis, dan 17,7 persen Liberal. Terkait dengan kelas sosial, responden penelitian ini mengaku sendiri sebagai berikut: 2, 6 persen kelas atas; 21,5 persen kelas menengah atas; 44,8 persen kelas menengah bawah; 15,8 persen kelas buruh; dan 7,7 persen kelas bawah.

Responden penelitian ini diajukan pertanyaan-pertanyaan dalam bentuk kuesioner seperti yang tampil dalam tabel di bawah ini. Responden mengisi sendiri pertanyaan-pertanyaan tersebut. Hasilnya adalah sebagai berikut:

\section{Tabel 1}

Pendapat Responden Kristen/Katolik di Medan Tentang Transformasi Moral Personal

\begin{tabular}{|c|c|c|c|c|c|c|}
\hline No. & Pertanyaan & & & & & \\
\hline 1 & $\begin{array}{l}\text { Menurut anda, pentingkah dibangun } \\
\text { masyarakat yang sejahtera? }\end{array}$ & $\begin{array}{l}\text { Sangat } \\
\text { penting } \\
79,7 \%\end{array}$ & $\begin{array}{l}\text { Penting } \\
19,7 \%\end{array}$ & $\begin{array}{l}\text { Agak } \\
\text { penting } \\
0,1 \%\end{array}$ & $\begin{array}{l}\text { Kurang } \\
\text { penting }\end{array}$ & $\begin{array}{c}\text { Tidak } \\
\text { penting } \\
0,3 \%\end{array}$ \\
\hline 2 & $\begin{array}{l}\text { Menurut anda, apakah penting dibentuk satu } \\
\text { keluarga yang bahagia? }\end{array}$ & $\begin{array}{l}\text { Sangat } \\
\text { penting } \\
78,1 \%\end{array}$ & $\begin{array}{l}\text { Penting } \\
17,9 \%\end{array}$ & $\begin{array}{c}\text { Agak } \\
\text { penting } \\
1,7 \%\end{array}$ & $\begin{array}{c}\text { Kurang } \\
\text { penting } \\
0,6 \%\end{array}$ & $\begin{array}{c}\text { Tidak } \\
\text { penting } \\
0,8 \%\end{array}$ \\
\hline 3 & $\begin{array}{l}\text { Setujukah anda, bahwa orang-orang yang } \\
\text { anda kenal hanya peduli dengan } \\
\text { kesejahteraan keluarga mereka sendiri? }\end{array}$ & $\begin{array}{l}\text { Sangat } \\
\text { Setuju } \\
6,7 \%\end{array}$ & $\begin{array}{l}\text { Setuju } \\
19,4 \%\end{array}$ & $\begin{array}{l}\text { Tidak } \\
\text { Setuju } \\
\mathbf{5 2 , 4 \%}\end{array}$ & $\begin{array}{l}\text { Sangat } \\
\text { Tidak } \\
\text { Setuju }\end{array}$ & \\
\hline
\end{tabular}




\begin{tabular}{|c|c|c|c|c|c|c|}
\hline & & & & & $20,7 \%$ & \\
\hline 4 & $\begin{array}{l}\text { Menurut anda, seberapa banyakkah orang- } \\
\text { orang yang anda kenal menyumbangkan } \\
\text { waktu dan uang untuk kemajuan } \\
\text { extendedfamily mereka? }\end{array}$ & $\begin{array}{l}\text { Banyak } \\
39,1 \%\end{array}$ & $\begin{array}{l}\text { Sedikit } \\
55 \%\end{array}$ & $\begin{array}{l}\text { Tidak } \\
\text { banyak } \\
4,5 \%\end{array}$ & & \\
\hline 5 & $\begin{array}{l}\text { Apakah penting bagi anda berdoa setiap } \\
\text { hari? }\end{array}$ & $\begin{array}{l}\text { Sangat } \\
\text { penting } \\
79,6 \%\end{array}$ & $\begin{array}{l}\text { Penting } \\
18,7 \%\end{array}$ & $\begin{array}{l}\text { Agak } \\
\text { penting } \\
0,4 \%\end{array}$ & $\begin{array}{l}\text { Kurang } \\
\text { penting } \\
0,4 \%\end{array}$ & $\begin{array}{l}\text { Tidak } \\
\text { penting } \\
0,4 \%\end{array}$ \\
\hline 6 & $\begin{array}{l}\text { Apakah penting bagi anda memberikan } \\
\text { sedekah, zakat atau sumbangan materi/ } \\
\text { uang sebagai karitas? }\end{array}$ & $\begin{array}{l}\text { Sangat } \\
\text { penting } \\
22,9 \%\end{array}$ & $\begin{array}{c}\text { Penting } \\
57,4 \%\end{array}$ & $\begin{array}{l}\text { Agak } \\
\text { penting } \\
10,2 \%\end{array}$ & $\begin{array}{l}\text { Kurang } \\
\text { penting } \\
5,9 \%\end{array}$ & $\begin{array}{c}\text { Tidak } \\
\text { penting } \\
1,3 \%\end{array}$ \\
\hline 7 & $\begin{array}{l}\text { Pernahkah anda membenci seseorang } \\
\text { karena agamanya berbeda dari anda? }\end{array}$ & $\begin{array}{l}\text { Sangat } \\
\text { benci } \\
2,9 \%\end{array}$ & $\begin{array}{c}\text { Benci } \\
\text { namun } \\
\text { tidak } \\
\text { selalu } \\
24,8 \%\end{array}$ & $\begin{array}{l}\text { Tidak } \\
\text { begitu } \\
\text { benci } \\
17,7 \%\end{array}$ & $\begin{array}{l}\text { Tidak } \\
\text { benci } \\
53,6 \%\end{array}$ & \\
\hline 8 & $\begin{array}{l}\text { Pernahkah anda bertegur sapa dengan } \\
\text { orang beragama lain di restoran, pusat } \\
\text { pasar, bank, angkutan umum atau di } \\
\text { jalanan? }\end{array}$ & $\begin{array}{l}\text { Selalu } \\
24,7 \%\end{array}$ & $\begin{array}{l}\text { Sering } \\
50,5 \%\end{array}$ & $\begin{array}{l}\text { Jarang } \\
20 \%\end{array}$ & $\begin{array}{c}\text { Tidak } \\
\text { Pernah } \\
3,1 \%\end{array}$ & \\
\hline 9 & Agama adalah sumber damai dan kasih. & $\begin{array}{l}\text { Sangat } \\
\text { Setuju } \\
77,5 \%\end{array}$ & $\begin{array}{l}\text { Setuju } \\
16,1 \%\end{array}$ & $\begin{array}{l}\text { Tidak } \\
\text { Setuju } \\
3,9 \%\end{array}$ & $\begin{array}{l}\text { Sangat } \\
\text { Tidak } \\
\text { Setuju } \\
1,3 \%\end{array}$ & \\
\hline 10 & $\begin{array}{l}\text { Berikut ini adalah warga yang pasti akan } \\
\text { anda tolak menjadi tetangga anda }\end{array}$ & $\begin{array}{l}\text { Warga } \\
\text { yang } \\
\text { seagama } \\
2,6 \%\end{array}$ & $\begin{array}{c}\text { Warga } \\
\text { yang } \\
\text { ateis/ } \\
\text { komunis } \\
82,9 \%\end{array}$ & $\begin{array}{c}\text { Warga } \\
\text { yang } \\
\text { berbeda } \\
\text { agama } \\
4,7 \%\end{array}$ & $\begin{array}{c}\text { Warga } \\
\text { yang } \\
\text { beragama } \\
\text { Hindu } \\
2,5 \%\end{array}$ & $\begin{array}{c}\text { Warga } \\
\text { yang } \\
\text { beragama } \\
\text { Budha } \\
1,8 \%\end{array}$ \\
\hline
\end{tabular}

- Warga Medan ketika ditanya "Pentingkah dibangun masyarakat yang sejahtera? dan "apakah penting dibentuk satu keluarga yang bahagia?", hampir 100 persen menjawab "penting". Kesejahteraan masyarakat dan kebahagiaan keluarga adalah dua hal yang penting bagi warga Medan.

- Ketika ditanyakan "Apakah orang-orang yang anda kenal hanya peduli dengan kesejahteraan keluarga mereka sendiri?" hampir 26 persen menjawab tidak dan 73 persen menjawab bahwa warga Medan peduli dengan kesejahteraan mereka yang lain. Hal ini dikonfirmasi oleh responden penelitian ini dalam pertanyaan selanjutnya: "Seberapa besarkah orang-orang yang anda kenal menyumbangkan waktu dan uang untuk kemajuan extendedfamily mereka?" Hampir 95 persen warga Medan berpendapat bahwa mereka membantu juga orang-orang yang mereka kenal dengan menyediakan waktu dengan mereka dan juga 
memberikan bantuan uang. Dengan demikian semakin nampak bahwa warga Medan memiliki kepekaan sosial yang tinggi. Mereka sangat mendambakan hidup yang bahagia dan sejahtera bukan hanya untuk diri mereka sendiri saja, namun bahagia dan sejahtera secara bersamasama sebagai umat manusia.

- $\quad$ Pertanyaan berikutnya terkait dengan kematangan hidup spiritual warga Medan. Hampir 99 persen warga Medan berpendapat bahwa berdoa itu penting bagi hidup mereka dan 80 persen menganggap bersedekah untuk karitas itu penting.

- Berkaitan dengan rasa benci terhadap pemeluk agama lain, ada 53,6 persen orang Medan yang tidak benci sama sekali dengan mereka yang non Kristen atau Katolik. Kalaupun ada yang membenci yang non Kristen/Katolik, jumlah mereka yang sangat membenci mereka yang beragama lain hanya 2,9 persen.

- Ketika berada di ruang publik (jalanan, angkutan umum, bank, restoran, dll) hanya 3,1 persen orang Medan yang tidak pernah bertegur sapa dengan mereka yang non Kristen/Katolik. Dengan demikian nampak bahwa kemungkinan besar mereka yang membenci pemeluk agama non Kristen/Katolik adalah juga mereka yang tidak pernah bertegur sapa dengan mereka.

- Ketika ditanya "Apakah agama adalah sumber damai dan kasih"? hampir 5 persen lebih orang Medan berpendapat bahwa agama bukanlah sumber damai dan kasih. Selebihnya, orang Medan setuju bahwa agama adalah sumber damai dan kasih.

- Pada pertanyaan terakhir, orang Medan kebanyakan (82,9 persen) menolak bertetangga dengan orang yang komunis/ateis. Hal ini bisa dimaklumi karena hampir semua orang Medan hidup dalam spiritualitas agama mereka sehingga mereka menolak orang yang menghidupi paham ateis (tidak adanya Tuhan).

Di atas telah dipaparkan tentang transformasi moral yang diperlukan untuk memperbaiki dekadensi moral di masyarakat. Penelitian ini berangkat dari fakta sosial yang ditemukan oleh Piet Go yang berkaitan dengan UU Perkawinan di Indonesia yang belum mempertimbangkan kesejahteraan individu-individu yang terlibat di dalamnya; pentingnya relasi inter-personal seorang gembala dengan umatnya; keterlibatan aktif Gereja untuk memperbaiki sistem hukum di Indonesia yang koruptif dan tidak manusiawi; serta sikap kerahiman Tuhan yang lebih dikedepankan dalam menghadapi masalah LGBT di masyarakat dan keluarga.

Masalah moral faktual yang berasal dari masyarakat tersebut kemudian ditelaah dan dicarikan solusinya: mengapa hal-hal tersebut terjadi dan bagaimana solusi pemecahannya. Peneliti berangkat dari ajaran sosial Gereja yang dimuat dalam Rerum Novarum dan Quadragesimo Anno yang menekankan bahwa untuk menyembuhkan masyarakat maka dibutuhkan 
transformasi moral. Transformasi moral masyarakat hanya bisa efektif bila setiap individu masyarakat melakukan transformasi atau yang disebut sebagai transformasi moral personal. Paul Hanly Furfey, sebagai sosiolog Katolik dari The Catholic Universityof America, meyakini bila setiap individu masyarakat melakukan transformasi moral personal tersebut lambat laun masyarakat akan sembuh. Furfey mengusulkan agar transformasi moral personal tersebut dimulai dengan perjuangan mewujudkan keadilan dan karitas.

Penelitian ini kemudian dirancang dengan menggunakan data dari penduduk Kristen/Katolik di kota Medan yang berasal dari survei sosial tahun 2010. Tujuan dari penelitian ini adalah untuk melihat secara konkret bagaimana transformasi moral personal yang digaungkan oleh Rerum Novarum dan Quadragesimo Anno diaplikasikan. Hasil penelitian menunjukkan bahwa warga Kristen/Katolik di Medan sudah meng-aplikasikan transformasi moral personal tersebut walaupun mereka tidak menyadarinya. Artinya, perhatian warga Kristen/Katolik di Medan untuk perwujudan keadilan dan karitas sudah dilaksanakan. Pertanyaannya: apakah ini berarti bahwa masyarakat di kota Medan sudah sembuh dari penyakit-penyakit moral?

Berikut adalah model statistik yang dibentuk berdasarkan 10 pertanyaan yang disampaikan kepada warga Medan tersebut di atas untuk memprediksi dan menjawab pertanyaan "Apakah masyarakat Medan sudah sembuh dari penyakit-penyakit moralnya? Analisa Faktor digunakan untuk mereduksi pertanyaan-pertanyaan kuesioner (atau disebut juga variabel Endogen) menjadi hanya dua atau tiga variabel Eksogen (merupakan ekstrak dari pertanyaan kuesioner). ${ }^{24}$

Kesepuluh pertanyaan tersebut diekstrak dengan menggunakan principalcomponentsanalysis (PCA). PCA digunakan karena dianggap akan lebih banyak menangkap variasi-variasi dalam korelasi yang berpola antara variabel yang ada. Penggunaan PCA menghasilkan nilai Kaiser-Meyer-Oklin $(\mathrm{KMO})=0,683$. Nilai ini lebih besar sedikit dari nilai KMO yang direkomendasikan para ahli sebesar 0,600. ${ }^{25}$ Sedangkan nilai Bartlett's Test of Sphericity nya sebesar 614,647 dan signifikan $(0,000)$. Ini menunjukkan bahwa proses pelaksanaan analisa faktor dapat dilanjutkan walaupun nilai korelasi antar variabel yang ada hanya sedikit jumlahnya yang berada di atas 0,3 .

Selain itu, PCA juga menghasilkan 2 faktor (seperti yang diharapkan peneliti) yang menjelaskan berturut-turut 21,4 persen dan 12,5 persen variasi di antara variabel. Total variasi dari kedua variabel ini adalah 40 persen. Rotasi Oblimin digunakan untuk menganalisis kedua faktor yang dihasilkan PCA.

24 Barbara G. Tabachnick, \& Linda S. Fidell, Using Multivariate Statistics (New York: Pearson Education, 2007), 609.

25 Marjorie A. Pett, Nancy M. Lackey \& John J. Sullivan, Making Sense of Factor Analysis - The Use of Factor Analysisfor Instrument Development in Health Care Research (Thousand Oaks, CA: Sage Publications, 2003), 78. 
Rotasi tersebut menghasilkan loading yang cukup kuat di antara variabel dari kedua faktor seperti yang tampak pada Tabel 2.

\begin{tabular}{|c|c|c|c|c|c|}
\hline & \multicolumn{2}{|c|}{$\begin{array}{l}\text { Koefisien } \\
\text { Komponen }\end{array}$} & \multicolumn{2}{|c|}{$\begin{array}{l}\text { Koefisien } \\
\text { Struktur }\end{array}$} & \multirow{2}{*}{ Komunalitas } \\
\hline & $\begin{array}{l}\text { Loading } \\
\text { Faktor } 1\end{array}$ & $\begin{array}{l}\text { Loading } \\
\text { Faktor } 2\end{array}$ & $\begin{array}{l}\text { Loading } \\
\text { Faktor } 1\end{array}$ & $\begin{array}{l}\text { Loading } \\
\text { Faktor } 2\end{array}$ & \\
\hline $\begin{array}{l}\text { Penting dibangun masyarakat } \\
\text { sejahtera }\end{array}$ & 0,580 & & 0,566 & & 0,337 \\
\hline Penting dibentuk keluarga & 0,570 & & 0,517 & $-0,420$ & 0,365 \\
\hline bahagia & & & & 0,597 & 0,365 \\
\hline Peduli hanya dengan & & 0,582 & & & \\
\hline kesejahteraan keluarga sendiri & & & & & \\
\hline $\begin{array}{l}\text { Besar sumbangan waktu dan } \\
\text { uang }\end{array}$ & 0,685 & & 0,713 & & 0,512 \\
\hline Penting berdoa & 0,609 & 0,344 & 0,667 & & 0,489 \\
\hline Penting bersedekah/ karitas & & 0,720 & & 0,717 & 0,541 \\
\hline $\begin{array}{l}\text { Benci seseorang karena } \\
\text { agamanya berbeda }\end{array}$ & 0,334 & $-0,339$ & & $-0,447$ & 0,226 \\
\hline $\begin{array}{l}\text { Bertegur sapa dengan orang } \\
\text { beragama lain di ruang publik }\end{array}$ & & & & & 0,075 \\
\hline $\begin{array}{l}\text { Agama adalah sumber damai dan } \\
\text { kasih }\end{array}$ & 0,646 & & 0,673 & & 0,456 \\
\hline $\begin{array}{l}\text { Warga yang pasti akan ditolak } \\
\text { menjadi tetangga }\end{array}$ & & & & & 0,031 \\
\hline
\end{tabular}

Catatan: Angka yang dicetak tebal adalah angka yang dipertahankan dalam analisa.

\section{Tabel 2}

Koefisien Komponen dan Koefisien Struktur dari PCA dengan Rotasi Oblimin Untuk Dua Faktor Transformasi Moral Personal Warga Medan



Gambar 1

Scree Plot untuk Dua Faktor Transformasi Moral Personal Warga Medan 
Scree Plot pada Gambar 1 di bawah menunjukkan dua faktor yang dihasilkan dari hasil analisa yang menggunakan PCA. Gambar Scree Plot ini hanya untuk menegaskan bagaimana kedua faktor tersebut dihasilkan.

Setelah mendapatkan ke dua faktor yang dihasilkan oleh PCA, maka sekarang pertanyaan-pertanyaan kuesioner dapat diklasifikasikan dan diekstrak menjadi 2 variabel eksogen. Kedua variabel eksogen tersebut berasal dari 8 pertanyaan kuesioner yang menghasil nilai sebesar 0,3 ke atas. Faktor 1 diberi nama variabel Transformasi Moral Personal (5 variabel endogen), dan Faktor 2 diberi nama Egosentris dan Ruang Publik (3 variabel endogen).

Tahap selanjutnya adalah menciptakan model StructuralEquationModels (SEM). Model ini disebut juga model persamaan struktural. Dalam model ini diasumsikan secara spesifik arah hubungan antar variabel. Selain itu, model SEM ini digunakan untuk menguji teori yang diusulkan sesuai dengan model empirisnya.

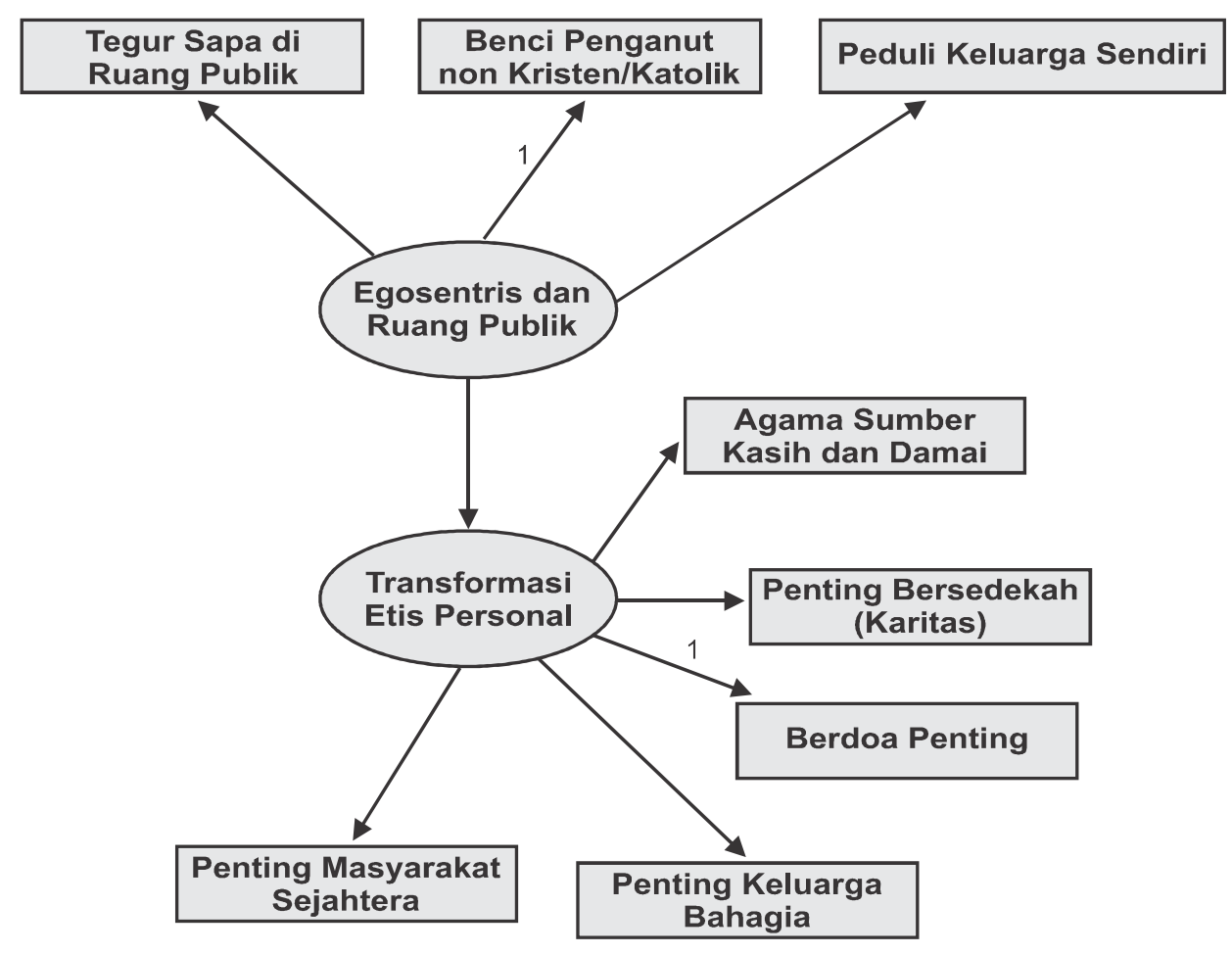

Gambar 2

Model Transformasi Etis Personal Warga Medan 


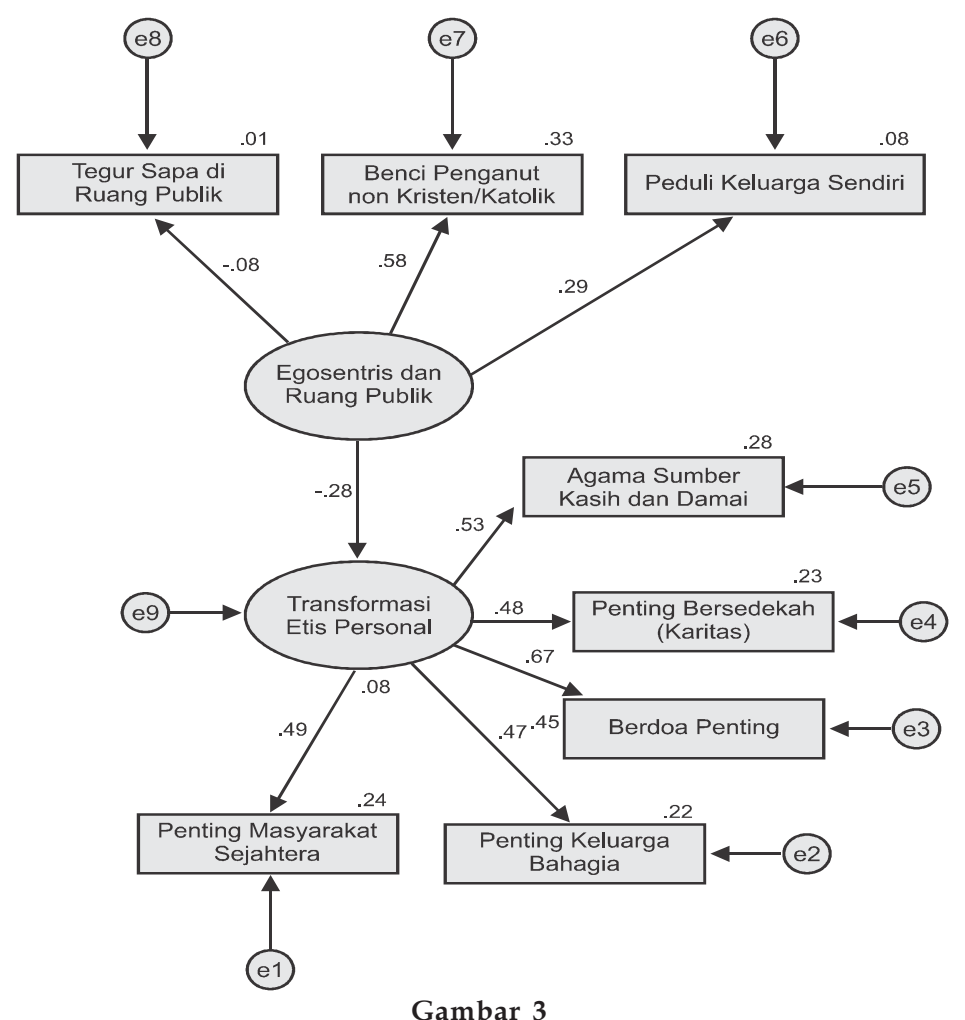

Model Transformasi Etis Personal Warga Medan

Model SEM yang diusulkan penulis adalah seperti yang tampak pada Gambar 2. Pada Model SEM tersebut ada 8 variabel endogen yang menyebar pada 2 variabel eksogen. Berdasarkan model tersebut, penulis menganalisis apakah model tersebut sudah sesuai dengan memperhatikan faktor-faktor yang mempengaruhinya.

Hasil analisa SEM dari model yang diusulkan penulis adalah sebagai berikut: Chi-square $=11,407$ dengan level probabilitasnya $=0,000$ (nilai probabilitas yang direkomendasikan ahli adalah berada sama dengan atau di bawah 0,05). Kemudian Root Mean Square Error of Approximation (RMSEA) model $=0,057$ (lebih kecil dari nilai maximum yang direkomendasikan ahli $=$ $0,08) .{ }^{26}$ Nilai NFI $=0,90$; CFI $=0,90$; dan IFI $=0,90$ model ini (persis sama dengan nilai minimum yang direkomendasikan ahli 0,90 ) membuktikan bahwa model SEM ini sudah cocok. ${ }^{27}$

Sekarang pertanyaannya adalah berapakah besaran perubahan yang akan dihasilkan oleh variabel Transformasi Moral Personal ketika variabel

26 Hair, J. F., Anderson, R. E., Tatham, Ronald L., \& Black, W. C., Multivariate Data Analysis (New Jersey: Prentice Hall, 1998) 655-57.

27 Ibid. 
Egosentris dan Ruang Publik berkurang atau bertambah? Koefisien regresi yang dimiliki variabel Egosentris dan Ruang Publik terhadap variabel Transformasi Moral Personal $=-0,28$. Sedangkan skor yang dimiliki oleh variabel Transformasi Moral Personal $=0,08$. Bila ada perubahan perbaikan pada variabel Egosentris dan Ruang Publik sebesar 0,10 poin, dengan demikian koefisien regresinya menjadi $-0,18$. Maka, diprediksikan akan ada perbaikan skor pada variabel Transformasi Moral Personal menjadi $=0,18$, demikian dan seterusnya. Demikianlah hitungan besaran perubahan variabel Egosentris dan Ruang Publik terhadap variabel Transformasi Moral Personal.

Kembali kepada pertanyaan di atas: "Apakah masyarakat Medan sudah sembuh dari penyakit-penyakit moralnya? Bila ada upaya-upaya dilakukan untuk menaikkan kesembuhan warga Medan dari penyakit moralnya, antara lain dengan memperbaiki skor pada pertanyaan-pertanyaan:

(1) Agama sumber kasih dan damai,

(2) Penting bersedekah (Karitas),

(3) Berdoa penting, maka diprediksikan akan ada perubahan skor sebesar 0,08 pada transformasi moral personal warga di Medan.

\section{Penutup}

Apakah transformasi moral, seperti yang telah diangkat ke permukaan oleh Piet Go memungkinkan untuk dilaksanakan? Jawabnya adalah bisa dan memungkinkan bila kita mengikuti petunjuk dari Paul HanlyFurfey yang mengatakan bahwa kekuatan transformasi moral itu ada pada setiap individunya. Transformasi moral masyarakat harus berangkat dari setiap individu di masyarakat. Tanpa keterlibatan aktif individu, maka transformasi moral tidak akan terjadi, dan masyarakat tidak akan sembuh. Penulis menggunakan data dari warga Medan untuk mengukur besaran perubahan transformasi moral bila setiap individu melakukannya. Penulis juga telah menciptakan model SEM untuk membantu mengukur pecaran perubahan tersebut. Semoga tulisan ini bermanfaat bagi kita semua.

\section{Kepustakaan}

Furfey, Paul Hanly. "Personalistic Social Action in the Rerum Novarum and Quadragesimo Anno". The American Catholic Sociological Review, Vol.II No. 4 (1941), 204-16.

Hair, J. F., Anderson, R. E., Tatham, Ronald L., \& Black, W. C. Multivariate Data Analysis. New Jersey: NJ, Prentice Hall, 1998.

Kristiyanto, A. Eddy. "Mengenali Konteks Ajaran Sosial Gereja Katolik Abad XIX". Orientasi Baru, Vol. 21, No.1, (April 2012), 35-54.

Mich, Marvin L. Krier. Catholic Social Teaching and Movements. CT: TwentyThird Publications, 2004. 
Pett, M. A., Lackey, N. R., \& Sullivan, J. J. Making Sense of Factor Analysis - The Use of Factor Analysis for Instrument Development in Health Care Research. Thousand Oaks, CA, Sage Publications, 2003.

Sianipar, Godlif. Christian-Muslim Relationship in Medan and Dalihannatolu: A Social Capital Study of The Batak Cultural Values and Their Effect on Interreligius Encounters. Dissertation. The University of Newcastle - Australia, 2012.

Tabachnick, B. G., \& Fidell, L. S. Using Multivariate Statistics. New York, NY, Pearson Education, 2007.

Tridiatno, Agus. “Masalah-Masalah Moral Masyarakat di Surat Kabar: Studi Kasus terhadap Halaman 'Kasus'. "Surat Kabar Harian Kedaulatan Rakyat". Jurnal Ilmu Komunikasi 2, no. 2 (Desember 2005): 161-74.

\section{Sumber Online}

Iman Katolik. "Kawin Campur Mengancam Gereja”. Diakses 18 Juli 2020. https://imankatolik.wordpress.com/2008/09/17/kawin-campur-mengancam-gereja/. Iman Katolik. "Banyak Umat Tidak Paham Salib". Diakses 18 Juli 2020. https://imankatolik.wordpress.com/2008/08/28/banyak-umat-tidak-paham-salib/. UCA News. "Theologian, Rights Activists Decry Death Penalty as Flawed, Wrong". Diakses 18 Juli 2020.

https://www.ucanews.com/story-archive/?post_name=/2003/03/07/theologianrights-activists-decry-death-penalty-as-flawed-wrongEpost_id=22103.

Majalah HIDUP Katolik. "Mereka Harus Kita Kasihi”. Diakses 18 Juli 2020. http://majalah.hidupkatolik.com/2016/11/14/1939/mereka-harus-kita-kasihi/.

Mission and Justice. "Theologians and the Use of Condoms". Diakses 18 Juli 2020.

http://wwww.missionandjustice.org/theologians-and-the-use-of-condoms/. 